\title{
Circuito productivo sojero y conflicto agrario en la Argentina. El año 2008 como hito y punto de inflexión
}

\author{
Soy production circuit and agrarian conflict in Argentina. The year 2008 as a milestone and turning point
}

\author{
Gastón Ángel Varesi \\ Instituto de Investigaciones en Humanidades y Ciencias Sociales, \\ Universidad Nacional de La Plata, CONICET, Argentina \\ gastonvaresi@hotmail.com
}

\section{RESUMEN:}

El artículo analiza el circuito productivo sojero, abordando sus dinámicas socio-económicas y territoriales, como parte de un subsistema de agronegocios más amplio. Asimismo, a partir de comprender dichos anclajes estructurales, se analiza el conflicto agrario de 2008 caracterizándolo como un hito en tanto estableció un punto de inflexión en la Argentina post-convertibilidad. Para ello, se propone un marco teórico-metodológico que recupera conceptos del enfoque de análisis regional y de la tradición marxista, conformando una mirada holística y relacional que hace foco en los procesos productivos y en la dinámica del conflicto, delineando un análisis de relaciones de fuerzas.

Palabras Clave: Circuito productivo regional, Soja, Subsistema espacial de acumulación, Agronegocios, Conflicto agrario.

\section{Abstract:}

The article analyzes the soy production circuit, addressing its socio-economic and territorial dynamics, as part of a broader agribusiness subsystem. In addition, after understanding these structural anchors, we analyze the agrarian conflict of 2008 , characterizing it as a milestone that established a turning point in post-convertibility Argentina. In order to accomplish this, we propose a theoretical-methodological framework that recovers concepts of the regional analysis approach and the Marxist tradition, forming a holistic and relational view that focuses on the productive processes and the dynamics of conflict, outlining an analysis of relations of forces.

KEYWORDS: Regional productive circuit, Soy, Spatial subsystem of accumulation, Agribusiness, Agrarian conflict.

\section{INTRODUCCIÓN}

El presente artículo se propone analizar las dinámicas del circuito productivo sojero en Argentina, en el marco del subsistema de agronegocios, para abordar el conflicto agrario que sacudió al país en el año 2008. Entendemos que dicho conflicto configura un hito en términos políticos, económicos y sociales, ya que instauró un punto de inflexión a partir del cual se delinearon características nodales en materia de hegemonía política e ideológica, que no pueden ser comprendidas sin analizar los anclajes económicos, sociales y territoriales con los que se articulan. La estrategia metodológica articula técnicas de análisis de datos cualitativos y cuantitativos, surgidos de fuentes primarias y secundarias, dentro de las cuales se destacan el análisis de documentos, leyes, discursos, fuentes periodísticas y bibliografía especializada, así como el análisis de series cuantitativas de organismos públicos, institutos científicos pertinentes e instituciones ligadas al sector. Con el objetivo de generar un estado de la cuestión actualizado, podemos señalar que el campo de estudios ligado a nuestro tema de investigación, si bien presenta una larga tradición, exhibe una prolífica variedad de desarrollos a partir del año 2008, estimulada por la necesidad de aportar claves explicativas en el marco del conflicto agrario. Esto se debe al carácter de hito que adquirió dicho conflicto y su impacto en el mundo académico. Este importante acervo bibliográfico puede ser sintetizado en distintos núcleos. En primer lugar, encontramos estudios de la producción sojera en Argentina que aportan un análisis global de las principales características económicas y territoriales (Barsky y Dávila, 2008; Basualdo, 2008; Bisang, 
2008; Arrillaga y Delfino, 2009; Barri y Wahren, 2010; Reboratti, 2010; Varesi, 2010; Pierri y Abramovsky, 2011; Albiol, 2013; Piergentelli y Dossi, 2014). Luego, encontramos un segundo núcleo de diversos trabajos que profundizan sobre dimensiones específicas del circuito sojero en Argentina, tales como su estructura exportadora y desempeño en materia de comercio exterior (Bugallo, 2012; Amaya Guerrero, 2014), la identificación de los distintos agentes económicos que participan del proceso productivo (Bustamante y Maldonado, 2009; Gras, 2012; Burgos, Mattos y Medina, 2014) así como el estudio de distintas producciones sectoriales que intervienen como medios para la producción agrícola, tales como las semillas, agroquímicos o maquinaria (Romero, 2014; Langard, 2016; Bil, 2017; Perelmuter, 2018; Pérez Trento, 2019). Asimismo, hallamos distintos trabajos que analizan con especificidad el conflicto agrario en la Argentina reciente. Por un lado, encontramos estudios que resaltan las dinámicas políticas del conflicto entreveradas con factores económicos y territoriales (Arceo y Rodríguez, 2008; Balsa, 2008; Giarracca, Teubal y Palmisano, 2008; Domínguez y Orsini, 2009; Gras y Hernández, 2009; Villulla, 2009; Manzanal y Arzeno, 2010; Teubal y Palmisano, 2010; Sanz Cervino, 2012; Varesi, 2014) y, por otro lado, encontramos trabajos que focalizan en la dimensión ideológica y la construcción de sentido, tanto a nivel del discurso construido por los distintos bloques en disputa (Fair Rzezak, 2008; Palma, 2011; Mengo y Pizarro, 2010) como en el destacado rol de los medios de comunicación (Ibáñez y Cabral, 2008; Becerra y López, 2009; Zunino y Aruguete, 2012).

Aun en esta fecunda producción académica, queda espacio para un trabajo que aporte a la integración de las distintas dimensiones y escalas de nuestro problema de estudio desde la particularidad de la perspectiva teórica aquí propuesta, la cual combina conceptos del enfoque de análisis regional con diversos autores provenientes de la tradición marxista, principalmente Antonio Gramsci. Tras delinear el marco teórico, abordaremos el análisis del circuito productivo sojero, dentro de un más amplio subsistema de agronegocios, para luego indagar los rasgos estructurales y las dinámicas hegemónicas del conflicto agrario de 2008, finalizando con algunas reflexiones para preguntarnos sobre la actualidad nacional.

\section{De LA HERENCIA DE MARX AL ANÁLISIS REgIONAL: SUBSISTEMA ESPACIAL DE ACUMULACIÓN Y CIRCUITOS PRODUCTIVOS REGIONALES}

El enfoque de análisis regional parte de la crítica a la noción tradicional de región, la cual implicaba una definición apriorística del objeto de estudio, con delimitaciones preestablecidas que difícilmente escapaban a los límites políticos provinciales o de expresar marco-regiones geográficas (Bandieri, 2005). A partir de allí, se propone una perspectiva alternativa donde la región comienza a ser vista como una construcción estrechamente ligada al problema de estudio que busca ser abordado y a las relaciones nodales que lo definen. Es en este sentido que De Jong (1981) expresa que la región empieza y termina donde empieza y termina su explicación. Asimismo, dicho autor nos convocaba a buscar las bases teóricas del método regional en las premisas del materialismo histórico (De Jong, 2001). Así, entendemos que en las principales definiciones conceptuales del análisis regional pueden encontrarse cuatro aspectos centrales que definen la herencia del pensamiento de Marx y que, en términos más generales, poseen influencia sobre las más diversas corrientes del pensamiento crítico en las ciencias sociales.

En primer lugar, Blanco (2007) sostiene que la geografía crítica parte de la conceptualización marxista de la relación entre los grupos humanos y la naturaleza, la cual posee una doble implicancia: la actividad humana transforma la naturaleza al tiempo que moldea el carácter humano y las relaciones entre las personas. Este aspecto se encuentra vinculado a las premisas del materialismo histórico, indicando que su análisis parte de la acción de los individuos orientada a producir sus medios de vida para la satisfacción de necesidades (Marx y Engels, [1846] 1985). Si somos lo que producimos y cómo lo producimos, nos encontramos aquí con un primer legado del pensamiento marxista: la centralidad de los procesos productivos. La acción transformadora y la satisfacción de necesidades, dan origen a los diversos modos de producción conformados por la unidad entre las relaciones sociales de producción (dentro de las cuales destacan la forma de propiedad de los medios 
productivos, la estructura de la sociedad y el modo de apropiación social del excedente) y el desarrollo de las fuerzas productivas (principalmente, la fuerza de trabajo y los medios de trabajo como herramientas, maquinaria e infraestructura).

Si, como señala Sánchez (1991), cada formación social presenta dentro de sus límites territoriales una síntesis jerarquizada de modos de producción, con la predominancia de uno de ellos, entonces los rasgos centrales de dicho modo de producción marcarán con sus lógicas y contradicciones la base del movimiento de las sociedades. Es en este proceso que los grupos sociales entran en relación y, al hacerlo, ponen en juego todo otro amplio conjunto de dimensiones políticas, jurídicas, ideológicas y culturales que componen las superestructuras, en una vinculación dialéctica. Esto nos lleva a un segundo aspecto clave del legado marxista: la perspectiva de totalidad. Desde una mirada crítica de la fragmentación del conocimiento, la perspectiva holística plantea una estrategia orientada a integrar múltiples dimensiones y múltiples escalas de análisis. Este aspecto es resaltado por Bandieri (2005) cuando señala que el análisis regional conlleva la idea de totalidad en tanto requiere aprehender los fenómenos globales involucrados en una región.

A su vez, la totalidad es presentada por Marx como un entramado de relaciones sociales, lo cual nos remite a un tercer aspecto de su legado: la perspectiva relacional. Si para Marx la sociedad no es un simple agregado de individuos sino la suma de las relaciones que se establecen entre ellos, esta mirada ha dejado su marca sobre el enfoque de análisis regional. Así, García y Rofman (2008) recuperan el carácter relacional del territorio, en tanto el mismo aparece definido no sólo por un conjunto de relaciones histórico-sociales sino por una relación compleja entre el proceso social y el espacio material. Desde allí, que el territorio sea movimiento, fluidez, temporalidad y pueda ser abordado como un proceso que se va definiendo en interacción con las múltiples dimensiones del poder.

Es factible aproximarse a estas relaciones de poder, desde una mirada gramsciana, entendiéndolas como relaciones de fuerzas (Gramsci, 2017), en sus distintos niveles y escalas. En razón de nuestro problema de estudio, se destacan dos momentos claves: a) las relaciones de fuerzas sociales, que remiten a un tipo de poder de carácter económico ligado al desarrollo de las fuerzas productivas y que implica analizar la posición y la función que los distintos grupos sociales poseen en la producción, y b) las relaciones de fuerzas politicas, vinculadas al grado de homogeneidad, organización y conciencia política colectiva, que trascurren desde el grado económico-corporativo hasta el plano superior donde se disputa la hegemonía a nivel del Estado, definiendo una unidad de fines políticos, económicos, intelectuales y morales, proyectados con una aspiración universal. Estos dos momentos, que pueden ser analizados en la escala nacional y regional, deben ser articulados con las tendencias provenientes de las relaciones de fuerzas internacionales, tanto a nivel de los rasgos orgánicos del modo de producción globalmente dominante como de la conformación de bloques de Estado hegemónicos y las disputas por la soberanía con las potencias y bloques menores.

Finalmente, estas relaciones constitutivas del proceso social no se dan de manera natural ni pacífica, sino que cobran forma a través de las disputas entre los grupos sociales por el excedente socialmente producido, en las luchas por dominar y por emanciparse como Marx y Engels (1960 [1948]) lo explicitaran en el Manifiesto Comunista. Así, las contradicciones constitutivas de lo real se dinamizan al calor de los antagonismos emergentes y por ello el cuarto elemento del legado marxista es la relevancia del conflicto como motor de la historia.

Estos legados que conforman una valiosa herencia del pensamiento de Marx tienen su incidencia en la construcción de diversos conceptos específicos creados para el abordaje de la escala regional.

Un primer concepto que se destaca es el de subsistema espacial de acumulación, desarrollado en Argentina por Levín (1981) y concebido como un instrumento metodológico orientado a dar respuesta a distintas problemáticas para el conocimiento y planeamiento regional. Si, como señala Trucco, el objetivo en última instancia del subsistema "es reconstruir el proceso de valorización de capital que atraviesa un fragmento espaciotemporal y su estructura” (2012, p. 28), un primer desafío que emerge es la delimitación del ámbito de observación. Frente a ello, Levín recupera la premisa básica del enfoque de análisis regional: dicho ámbito 
no debe quedar circunscripto a recortes preestablecidos, sino que debe ser guiado por la primacía de las relaciones sociales que constituyen un nudo problemático que se busca analizar. Además, Levín plantea que el diseño de subsistemas debe estar compuesto por un conjunto de empresas que pueda ser visualizado como si constituyeran un todo. Señala también que esa totalidad está conformada por agentes económicos que están recíprocamente condicionados a través de relaciones directas de desigualdad que establecen según su poder de acumulación. Esto se vincula a que "normalmente las operaciones con reducidas tasas de ganancia son indispensables para las secuencias con elevados rendimientos" (Crespo, 1998, p. 119), por lo cual el desempeño negativo de algunos agentes económicos no es una fatalidad o falla del subsistema sino que es una tendencia estructural de la propia acumulación capitalista; de allí que sea necesario identificar correctamente los mecanismos que operan para cristalizar dichas transferencias de recursos y así poder operar efectivamente sobre las mismas.

En esta línea, De Jong sugiere que el papel que desempeña la generación y distribución de la riqueza se verá expresada en aquello que refiere a los subsistemas de acumulación en distintos factores tales como:

*la organización del trabajo para la generación de plusvalor y de su transformación en capital (apropiación de excedentes), *las relaciones sociales que conducen a la acumulación desigual de excedentes, particularmente a través de los mecanismos de la reproducción ampliada del capital, *la fuente y el ejercicio del poder que emerge del control de éstos y de las instituciones que constituyen el ámbito de su ejercicio, * ${ }^{*}$ a respuesta del medio social a los requerimientos de la generación de excedentes en un sistema social dado, *los fenómenos asociados a nivel de la conciencia social y su materialidad (De Jong, 2009, p. 63).

El análisis de relaciones de fuerzas sociales implica ver la capacidad de incidir en el subsistema a través de la posición, la función y poder que los distintos grupos sociales detentan. Y esta desigualdad estructural no sólo opera entre las clases sociales, sino también al interior de las mismas, lo que se traduce en que el más "grande", que concentra y ocupa posiciones centrales de poder, pueda imponerle a los más "pequeños" condiciones que generan transferencia de valor, por ejemplo fijándole el precio de compra-venta, criterios de calidad del producto o induciendo las formas de inserción de aquellos en el proceso productivo, etc.

A su vez, las relaciones de fuerzas políticas tienen su incidencia en los distintos grados de las mismas. En el plano económico-corporativo se juega la capacidad de presión de los distintos grupos sociales por expresar y defender sus intereses sectoriales. En el grado económico general, debe evaluarse la capacidad colectiva del sector de influir en la conducción de clase en su conjunto en el plano de la economía nacional. Y finalmente, en el momento superior, estrictamente político, debemos indagar cómo las fracciones de clases constituidas en bloque de poder avanzan a gestar la construcción de hegemonía a nivel Estado. Esto implica desarrollar capacidad de dirección, conformando una visión del mundo, que dé base a un proyecto que encarne en fuerza política y se difunda por toda la sociedad, involucrando un proceso de universalización de intereses, con predominio de los generales, y articulación de concesiones a los grupos subordinados. Aquí, el análisis de la política pública, la relación de los grupos del bloque de poder con las fracciones y agentes del subsistema estudiado, y su incidencia en el establecimiento de las "reglas de juego", constituyen factores relevantes para comprender la dinámica de las relaciones de fuerzas políticas en un subsistema.

Otro concepto de alta relevancia para nuestro problema de estudios es el de circuito productivo regional, con el cual Rofman genera una herramienta teórico-metodológica que recupera los pilares fundamentales del planteo de Levín, pero que posee un mayor nivel de especificidad. El circuito productivo regional parte de seleccionar como base una materia prima cualquiera y se considera al circuito como integrado por productores de la misma, transformadores de sucesivos productos manufacturados que, asimismo, participan de la etapa siguiente como insumos hasta la fase del consumo final, y se incorpora también a los procesos de comercialización y financiamiento (Rofman, 1984).

De este modo, un circuito productivo es un encadenamiento particular en que puede desdoblarse un subsistema espacial de acumulación. Rofman (1984) reconoce dos tipos generales de interrelaciones entre circuitos dentro de un subsistema. En primer lugar, una vinculación directa en términos de relaciones técnicas de producción, cuando un eslabón de cierto circuito requiere insumos de otro circuito. En segundo lugar, 
hay relaciones indirectas en dos modalidades; una es a través de la generación de excedentes en un circuito en que se derivan hacia otro circuito distinto vía financiamiento; otra modalidad sería por medio de la fuerza de trabajo, generando movimientos interempresariales de fuerzas de trabajo.

Finalmente, para el análisis de un circuito productivo regional, Rofman (1999) propone distintos aportes metodológicos. En primer lugar, se plantea la necesidad de identificar el modo de producción dominante que rige el circuito. En segundo lugar, debemos reconocer las formas técnicas de producción predominantes, utilizadas por los diferentes agentes económicos en los eslabones que conforman el circuito. Como tercer aspecto, se sugiere detectar las actividades dominantes que actúan como eje central del circuito y alrededor de las cuales se articula el proceso de determinación de precios y las modalidades de acumulación. Finalmente, es necesario avanzar hacia la elaboración de una tipología de agentes y de la fuerza de trabajo, identificando quiénes ocupan posiciones dominantes y subordinadas.

\section{SubSistemA DE AGRonegocios y CIRCUITO PRODUCTIVO SOJERO}

El problema de estudio nos guía a la delimitación de un subsistema de agronegocios centrado en los tres cultivos de mayor gravitación a nivel nacional: soja, maíz y trigo. Estos poseen factores comunes que permiten agruparlos: comparten territorio, dinámicas productivas y tecnológicas, agentes económicos, actores corporativos y están atravesados por similares políticas y problemáticas. Así, encontramos dos aspectos comunes al subsistema que implican tendencias de largo plazo que se han ido acelerando en las últimas décadas.

El primero refiere al proceso de agriculturización y se expresa en dos niveles. Un primer nivel alude a la tendencia expansiva de la agricultura a ritmos muy superiores al de la ganadería, con el desplazamiento de esta última de las mejores tierras y su vuelco hacia formas más intensivas. Según Reboratti (2010) desde los inicios de la expansión agrícola, principalmente impulsada por la soja, se perdieron 4 millones de vacunos y 2 millones de ovinos, reconvirtiendo 4 millones de hectáreas.

Un segundo nivel refiere a la expansión de la frontera agraria. Si la superficie sembrada creció un $15 \%$ entre los censos agropecuarios de 1988 y 2002, la superficie ligada a la producción de maíz, soja y trigo que conforma nuestro subsistema espacial de acumulación adquirió ritmos muy superiores pasando de 12.087 .894 ha en la campaña $1987 / 1988$ a 21.808 .221 ha en $2001 / 2002$, creciendo el $80,4 \%$, hasta alcanzar los 32.907 .871 ha en 2016/2017, superando una expansión del $172 \%$ en total. Esto implicó una expansión del subsistema hacia espacios cada vez más alejados de su "zona núcleo" pampeana y conllevó un fuerte impacto en el noreste y noroeste argentino, desplazando cultivos tradicionales e implicando conflictos a raíz de la expulsión del campesinado originario en distintas zonas. Asimismo, involucra un serio impacto ecológico ligado a la pérdida de bosques nativos, teniendo en cuenta que en el periodo 1998/2002 se deforestaron 763.733 ha, sumando otras 1.193.206 ha en 2002/2006 y 1.415 .002 ha de 2006 a 2011, particularmente en las provincias de Santiago del Estero, Salta, Córdoba, y Chaco (Domínguez y Orsini, 2009).

El proceso de agriculturización se encuentra vinculado a las transformaciones técnicas de largo plazo conocidas como "revolución verde". Estas implican un cambio en la composición orgánica del capital, donde el capital fijo ligado a las innovaciones en maquinaria e insumos va incrementándose mientras se reduce el capital variable, es decir, la mano de obra necesaria para las labores agrícolas, conformando la imagen de una “agricultura sin agricultores".

Asimismo, se evidencia que dentro del subsistema hay un circuito productivo que resalta por su dinamismo, como puede observarse en el gráfico $\mathrm{N}^{\circ} 1$. 


\section{GRÁFICO 1}

Superficie sembrada de maíz, soja y trigo, 1976/77 - 2016/17

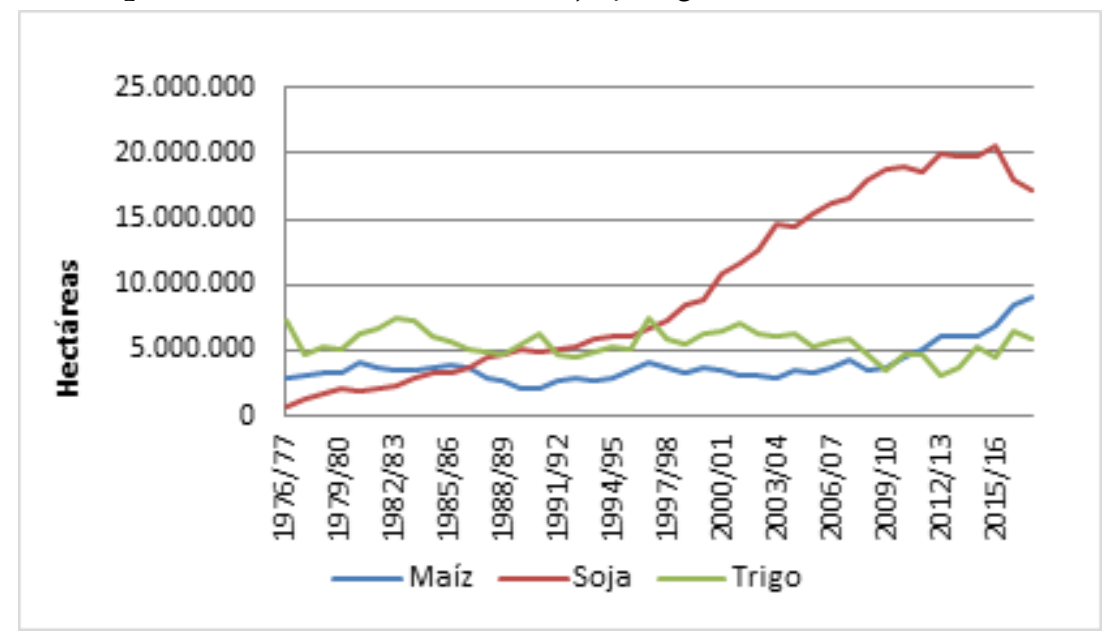

Elaboración propia en base a Estimaciones Agrícolas (MAGyP).

Así, observamos que el proceso de agriculturización en Argentina está articulado con un proceso de sojización. Esto se debe al dinamismo que ha cobrado el circuito productivo sojero por encima de los restantes, que implica que la soja llegue a ocupar el $60 \%$ del área total sembrada y que exista una evolución disímil entre los distintos cultivos del subsistema, la cual fue muy marcada en la década previa al conflicto agrario: si comparamos la campaña 1996/1997 con la de 2006/2007, mientras que la producción en toneladas de granos de soja había aumentado un 331 \%, la de maíz lo había hecho en 40 \% y la producción de trigo se había reducido en un $8 \%$ (MECON, 2011).

Aquí las transformaciones en las técnicas productivas constituyen un factor central. El largo proceso de "revolución verde" dio un salto con el desarrollo del denominado "paquete tecnológico", el cual combina tres elementos que interactúan entre sí.

En primer lugar, encontramos las semillas genéticamente modificadas. La primera que se introdujo al país fue la soja RR de Monsanto en 1996, cuyo nombre se vincula a su resistencia al glifosato, principal componente del herbicida Roundup Ready producido por la misma empresa. Al año 2019 encontramos 60 semillas genéticamente modificadas aprobadas, dentro de las cuales se encuentran distintos eventos genéticos para soja y maíz (también se están produciendo localmente investigaciones sobre el trigo).

El segundo componente del paquete tecnológico son los agroquímicos, tanto fitosanitarios como fertilizantes. Según consigna un estudio de la Defensoría del Pueblo de la Provincia de Buenos Aires y la UNLP, bajo las lógicas productivas del actual paquete tecnológico, en materia de agroquímicos "la soja cumple un rol fundamental, ya que es el principal responsable del crecimiento de la utilización de agroquímicos en la República Argentina, demandando alrededor del $46 \%$ del total de plaguicidas utilizados por los agricultores" (2015, p. 14). También se sostiene que la masificación del uso de agroquímicos conlleva numerosos riesgos para la salud pública.

Como tercer componente se encuentra la siembra directa, la cual, según el INTA, "es parte de un sistema integral de producción de granos que evolucionó hacia la implantación del cultivo sin remoción del suelo y con cobertura permanente del suelo con residuos de cosecha" (2011, p. 1). El mismo estudio señala que la Argentina es líder mundial en la adopción de la siembra directa abarcando el $81 \%$ del área total cultivada. Esto presenta un claro incremento en relación a "lo que ocurrió en la campaña 1996/97 en la que la misma representó el $15 \%$, coincidiendo el incremento con la introducción del paquete tecnológico: soja transgénica, glifosato, y otros productos vinculados" (Burgos, Mattos y Medina, 2014, p. 32). Asimismo, el INTA señala un conjunto de beneficios en materia económica al prescindir este sistema de la labranza tradicional, reduciendo así las horas de trabajo necesarias, y también una mejor conservación del suelo, al 
protegerlo de la erosión y mejorar el aprovechamiento del agua. Sin embargo, Reboratti (2003) sostiene que en este sistema, como contrapartida, las pestes y malezas se difunden muy rápidamente llevando a un empleo masivo de biocidas, con sus problemáticos efectos sobre el medioambiente y la salud.

Otros cambios técnicos, como la utilización de información satelital de georeferenciación y mapeo del suelo, que permiten detectar la heterogeneidad de un terreno y generar estrategias de optimización, vienen configurando una genuina Agricultura de Precisión. Esto, sumado al sistema de silobolsas y la posibilidad de realizar un doble cultivo con soja de segunda y trigo de ciclo corto, han añadido novedades que potencian el despliegue del subsistema.

Los cambios técnicos suscitados dentro del subsistema espacial de acumulación nos permiten caracterizarlo como un modo de producción capitalista con altos índices de desarrollo técnico y tecnológico, que genera asimismo profundas transformaciones en las dinámicas específicas del circuito productivo sojero, al tiempo que es liderada por este circuito a través de la dinámica agriculturización-sojización.

En este camino, la aplicación del "paquete tecnológico" representó una disminución en los costos en relación al beneficio, debido al aumento importante en el rendimiento, el cual para el caso de la soja pasó de promediar los $2055 \mathrm{~kg} / \mathrm{ha}$ entre las campañas de 1986/87 y 1996/97, para alcanzar los $2660 \mathrm{~kg} / \mathrm{ha}$ entre 1997/98 hasta 2016/17, implicando un alza promedio del 29,4\% (datos MAGyP). Sin embargo, acceder al paquete tecnológico requiere de una elevada inversión de capital, lo cual amplía la escala necesaria para su aplicación y conlleva distintos efectos sobre los agentes económicos.

En este sentido, se torna necesario generar un esbozo global de la tipología de agentes vinculados al circuito productivo sojero.

En un primer núcleo encontramos a los productores de medios de trabajo, es decir, de insumos y bienes de capital. Por lo que dentro del mismo podemos distinguir dos grupos. Por un lado, se ubican los productores semillas y agroquímicos.

El mercado de semillas a nivel mundial se encuentra concentrado en sólo cuatro empresas (MonsantoBayer, Syngenta-ChemChina, Dow-DuPont y BASF) que controlan el 59,8 \% de dicho mercado (Rebagliati, 2017). El caso de la soja genéticamente modificada en la Argentina fue introducida inicialmente por Monsanto, pero al carecer del patentamiento necesario, en un marco legal que sostiene el derecho de resiembra del productor y el desarrollo del mercado ilegal de la denominada "bolsa blanca" en un contexto de baja fiscalización, ha dado lugar a un vasto conflicto que hasta el vencimiento de la patente en el exterior de la soja RR fue saldado a favor de los productores (Pérez Trento, 2019). Asimismo, se han ido afianzando en el sector otros agentes de capital transnacional como Nidera y Syngenta (en 2018 la segunda adquirió a la primera), junto a algunas de capital nacional, como Don Mario.

El mercado de agroquímicos fitosanitarios era liderado, hacia 2003, por Monsanto a través de la marca Roundup, concentrando un $65 \%$ de las ventas de glifosato, aunque esta situación monopólica se fue erosionando y cuando terminaron las patentes a nivel internacional la oferta de dicho producto fue acaparada por importaciones de China a más bajo costo (Romero, 2014). Por su parte, el mercado de fertilizantes también posee una estructura oligopolizada, "en el que el abastecimiento del mercado local se encuentra en un $80 \%$ en manos de Profertil y Bunge, sumándose grandes empresas comercializadoras (Cargill, Nidera, ASP y Yara), que actúan como importadores, agentes intermediarios y grandes distribuidores mayorista" (Romero, 2014, p. 92).

En todo el núcleo de insumos se destaca la relevancia del monopolio tecnológico, concentrado en grandes transnacionales cuyas áreas de I+D suelen permanecer en las economías centrales.

Por su parte, el grupo ligado al mercado de maquinaria agrícola, que provee de dichos bienes de capital al circuito sojero, presenta una concentración territorial en la provincia de Santa Fe, donde se ubica el 45 \% de las empresas. Asimismo, según Langard, muestra dos segmentos diferenciados:

Por un lado, el segmento de tractores y cosechadoras conformados por empresas de gran tamaño, insertos en cadenas globales de valor con elevada productividad y altos grados de externalización, pero con un bajo coeficiente de exportaciones. Por 
otro lado, el segmento de sembradoras en el cual predominan empresas nacionales relativamente integradas y con menores coeficientes de importaciones, que se caracterizan, a su vez, por una incipiente competitividad en mercados externos (2016, p. 414).

Otros trabajos también destacan el desempeño positivo que ha tenido la producción nacional de sembradoras, la cual ha cubierto el $97 \%$ de la oferta local entre 2010 y 2012 (PwC, 2013). En un segundo núcleo podemos ubicar a tres agentes claves del proceso productivo: los productores, rentistas y contratistas. Según Bustamante y Maldonado,

el productor agropecuario tradicional es aquel sujeto social que aún mantiene su explotación -propia o arrendada-y que lleva adelante procesos productivos agropecuarios, pudiendo contratar servicios de maquinaria y de laboreo en algunos casos, pero sin delegar el control y la responsabilidad de los procesos (2009, p. 183).

Por su parte, los rentistas son los propietarios del suelo que alquilan su tierra para ser trabajada por otro, recibiendo por esto una renta en dinero o especies. El avance del rentismo se encuentra vinculado, por una parte, al cambio de escala debido al alto nivel de inversión que requiere la conversión productiva ligada al "paquete tecnológico" y, por otra parte, a que el incremento del valor de la tierra arrastró tras de sí el precio de los alquileres. Según Barsky y Dávila (2008), ya entre 2002 y 2007 el precio de la hectárea en la zona maicera pampeana pasó de USD 2.692 a 8.700, lo que llevó a un alza del precio de los alquileres. Fue así que muchos productores optaron por convertirse en rentistas, obteniendo una renta de entre USD $400 \mathrm{y}$ 500 por ha. Este proceso se profundizó ya que, según Burgos, Mattos y Medina (2014), al año 2012 el valor de la tierra en el agro pampeano se había incrementado un 557 \% en relación a 2002. Por ello, más allá de si se dedican a la producción o al rentismo, los grandes terratenientes siguen siendo agentes poderosos del agro argentino. Por otra parte, cobran creciente relevancia los contratistas, propietarios de maquinaria que realizan tareas de siembra, cosecha y fumigación, y que abarcan una serie de variaciones en su desempeño: trabajando el campo de terceros, por dinero o especies, por un monto fijo o variable según producción, siendo o no propietario ellos mismos de una explotación agropecuaria. Según FACMA, son responsables de más del $60 \%$ del componente de labores de la producción granaria. Estos tres grupos presentan heterogeneidad también en su interior según su poder de mercado.

Un tercer núcleo está vinculado al acopio, es decir, a las actividades de almacenamiento, que se articulan también con el secado de granos, provisión de insumos, transporte y comercialización. Estos agentes se distinguen entre particulares y cooperativos, con capacidad de almacenaje del $70 \%$ y el $30 \%$ respectivamente. Según Llovera, para el sector granario en general,

más del $70 \%$ de los insumos llega al productor vía acopio. Con su manejo profesional optimiza la circulación de los granos en espacio y tiempo (transporte y almacenamiento). El $80 \%$ de los productores utiliza el servicio de transporte a planta brindado por el acopio, con lo que se asegura un fluir ordenado y de calidad homogénea de los granos a los centros de industrialización y exportación (2006, p. 46).

Asimismo, ejercen un rol de intermediación que atenúa los efectos de una demanda concentrada frente a una oferta de producción atomizada.

Un cuarto núcleo está compuesto por los grandes gestores y organizadores del proceso productivo, dentro de los que resaltan los pools de siembra y las megaempresas agropecuarias. El pool de siembra representa una modalidad coyuntural de carácter financiero que articula diversos eslabones de los circuitos agrícolas, pudiendo recorrer desde la compra de insumos hasta la exportación. Esta modalidad se abre paso a partir de la constitución de fideicomisos o fondos de inversión y puede implicar desde la articulación de pequeños productores con el objetivo de aumentar la escala y disminuir costos, hasta la configuración de gigantescas operaciones coordinadas por conglomerados financieros locales o transnacionales.

Las megaempresas agropecuarias, a diferencia de los pools, son de carácter permanente y articulan distintos factores para ganar escala y capacidad de acumulación. Estas 
se organizaron siguiendo la lógica de la tercerización típica de la empresa toyotista, algo que en el campo argentino generó un nuevo fenómeno histórico: la del pequeño y mediano propietario rural volviéndose arrendadores (rentista), así como la eventual desaparición del pequeño arrendatario. Es la gran empresa la que se volvió arrendataria, ocupando un lugar históricamente relacionado con el pequeño productor (Godio y Robles, 2008, p. 155).

Según Gras, estas son "empresas con acceso y control del capital financiero, que manejan el know-how de gestión y el management" (2012, p. 467). Un caso destacado es el de Los Grobo, que gestiona unas 188.000 ha, concentrando capacidad de almacenamiento, procesamiento y clasificación de semillas, transporte y molienda.

En el quinto núcleo encontramos a las empresas dedicadas a la industrialización del grano y a la exportación. El Ministerio de Economía (2011) calcula que un 75 \% de la producción primaria de soja se destina a la industrialización, segmento que presenta una alta concentración, en tanto 7 empresas (Cargill, Molinos Río de la Plata, Terminal 6, Louis-Dreyfus, Bunge, Vicentín y Oleag. San Lorenzo) de las 37 productoras de aceites concentran el $72 \%$ de la capacidad instalada de molienda, al tiempo que suelen estar integradas con otras actividades de la cadena como la producción de semillas, siembra de oleaginosas en campos propios, producción de fertilizantes, almacenamiento y terminales portuarias propias, lo que permite la comercialización, exportación de granos y producción de aceites y pellets. Similar escenario de concentración se encuentra en la exportación de granos de soja, donde las primeras 4 empresas (Cargill, Noble Grain, ADM y Bunge) exportan más de la mitad del volumen exportado y las 10 más grandes explican el $96 \%$.

Si encontramos 5 núcleos ligados al polo del capital, en cada uno de ellos encontramos al polo del trabajo. Los trabajadores rurales presentan una amplia diversidad: desde aquellos que, a cambio de un salario percibido en dinero y generalmente complementado con alimentación y vivienda, venden su fuerza de trabajo a un productor rural, o aquellos que trabajan para un contratista operando la maquinaria agrícola, o en el sector acopiador-comercializador de granos, cereales o ganado, entre otros (Bustamante y Maldonado, 2009). En un marco legislativo, recién reformado en 2011, los trabajadores rurales tienden a poseer menores derechos en relación a los restantes sectores de la economía, con un elevadísimo nivel de informalidad y bajas remuneraciones, por lo que no se cuentan entre los beneficiarios del auge de los agronegocios. Según Godio y Robles, la retracción del salario de los trabajadores rurales en dólares desde la devaluación de 2002 frente al fuerte incremento de rentabilidad de los agentes propietarios implicó que "la transferencia de ingresos mediante ese proceso, de los trabajadores a los propietarios y arrendatarios rurales, puede ser estimada en unos 2.000 millones de dólares anuales" (2008, p. 164). Según un estudio de caso desarrollado por el CENDA (2008) en Pergamino, en la zona núcleo sólo el 3,0 \% del valor agregado se destinaba al pago de salarios directos, y si se incluyen como parte de las remuneraciones los posibles gastos salariales en estructura, en el caso de la producción de soja, ese porcentaje estaría en tre el 6,0 \% y el 8,8 \%, según los rendimientos obtenidos con el cultivo, por lo que las ganancias y rentas del capital acaparaban entre el 91,2 \% y el 97,0 \%.

En el circuito sojero, según Schvarzer y Tavosnanska (2007), del ingreso bruto cerca de la mitad se utiliza para cubrir los costos de producción y distribución, siendo captada por los productores de insumos, los intermediarios, los transportistas, etc., y el resto es ingreso del productor, o se divide entre arrendatario y dueño de la tierra. Asimismo, estos autores señalan que, en la cadena, parte se "derrama" aguas abajo mientras que el resto es apropiado por los actores con suficiente poder de mercado como para captar parte de la renta, como los propietarios de grandes extensiones de tierras, productores que controlan mediante el arrendamiento gran parte de la producción, las grandes empresas aceiteras y productores de insumos.

De este modo, la asimetría en la asignación de recursos que se presenta entre las clases sociales también tiene expresión al interior de las propias clases, evidenciada en la heterogeneidad presente en el polo del capital. Allí, identificamos un triple proceso de concentración: A) Concentración en el uso de la tierra, donde en el circuito sojero sólo el $6 \%$ de los más grandes productores que producen en una escala mayor a las 1500 ha explican el $54 \%$ del total producido, mientras que como contraparte el $94 \%$ de los productores dan cuenta del $46 \%$ restante. B) Esto está sin dudas ligado también a la concentración de la gestión y organización del proceso 
productivo, con la conformación de los grandes pools de siembra y las megaempresas agrícolas rigiendo las dinámicas del sector. C) Finalmente, se expresa también en la concentración del capital, tanto en los primeros eslabones con la producción de semillas y agroquímicos como en quienes concentran la capacidad de desarrollo biotecnológico, de la maquinaria en los contratistas y de la industrialización y exportación en un reducido y poderoso grupo de empresas.

\section{EL CONFLICTO DE 2008 COMO HITO: ANCLAJES ESTRUCTURALES Y DINÁMICA HEGEMÓNICA}

Desde una perspectiva de totalidad, debemos aprehender la incidencia de fenómenos de distintas dimensiones y escalas con el fin de poder analizar el caso del conflicto agrario de 2008, ya que consideramos que el mismo constituye un hito, en tanto trascendió su propia coyuntura estableciendo un punto de inflexión en las dinámicas políticas, económicas y sociales de nuestro país.

En este sentido, como señalaba Rofman (1999), las dinámicas de un circuito productivo regional no pueden ser indagadas sólo por las tendencias presentes en dicha escala sino en relación con el contexto nacional e internacional en el cual se desenvuelve. Por ello, la relación entre el modelo de acumulación y el circuito adquiere relevancia. Durante el modelo de la convertibilidad se ejercieron las reformas estructurales que llevaron a la "revolución verde" a un nuevo estadio. En primer lugar, el cambio en la relación Estadomercado derivó en una desregulación del sector, con disolución de entes reguladores como la Junta Nacional de Granos, desfinanciamiento de institutos estatales de investigación como el INTA y retracción de créditos preferenciales hacia pequeños y medianos productores, lo que abrió cauce al proceso de financiarización. En segundo lugar, en 1996 mediante la resolución 167, se habilitó la libre producción y comercialización de las semillas de soja genéticamente modificadas resistentes al glifosato. Esto se dio junto a la apertura comercial que favoreció a quienes tenían el capital suficiente como para avanzar hacia la reconversión tecnológica, motivando una mayor concentración. En tercer lugar, mientras la quita de retenciones favorecía al sector, la apreciación cambiaria cristalizada en la convertibilidad de la moneda 1 \$-1USD le restaba recursos.

Tras la crisis de 2001 y la configuración de un modelo productivo-exportador de carácter neodesarrollista desde 2002, el agro fue beneficiado con la licuación de deudas pesificadas, la nueva política de dólar alto, la regulación de tarifas de servicios y precios de combustibles, en un contexto de alza de los precios internacionales. Como contraparte se restablecieron las retenciones, más altas para los productos primarios y menores para aquellos con valor agregado. Así, los agentes del agronegocio constituían parte de las principales fracciones beneficiarias del neodesarrollismo, ya que podemos ubicarlos dentro de la fracción productivoexportadora del capital, ascendente al interior del bloque de poder, en un contexto de subordinación relativa de la fracción financiera del capital y de la fracción de empresas de servicios públicos principalmente privatizadas.

Fue en el marco de un alza pronunciada de los commodities agrarios, en un corto plazo, donde el recientemente asumido gobierno de Cristina Fernández de Kirchner (CFK) lanzaría la Resolución 125 del Ministerio de Economía a cargo de Martín Lousteau, el 10 de marzo de 2008. El precio internacional de la soja presentaba un incremento del $118 \%$ en sólo un año, alcanzando los 566 dólares, por lo que esta resolución establecía en su artículo 1 una ecuación que implicaba la creación de un sistema de retenciones móviles para cereales y oleaginosas y, en los artículos 2 y 3 , asentaba los nuevos valores que variaban según el precio internacional de las diversas mercancías. El nuevo esquema presentaba un fuerte aumento de los derechos de exportación para soja, llevándola en aquella coyuntura del $35 \%$ fijo previo a un $44 \%$ móvil, y una leve merma de los mismos para trigo y maíz. Esta propuesta de retenciones móviles poseía una debilidad de origen: no establecía diferenciaciones entre los distintos agentes del heterogéneo universo agrario y además fijaba que, cuando los precios internacionales alcanzaran los 600 dólares, la alícuota aumentaría al punto de afectar el $95 \%$ del valor que sobrepasara dicho monto, implicando un virtual precio máximo que complicaba los mercados de futuro, limitando dicha vía de financiamiento. 
La respuesta de las patronales agrarias no se hizo esperar, dando inicio a la protesta el 11 de marzo. Comprender el conflicto con su capacidad de dinamizar el proceso histórico y conformar un hito que altera las distintas dimensiones de la sociedad, implica, desde nuestro enfoque, abordar los rasgos y variaciones en las relaciones de fuerzas. El análisis de las dimensiones económicas y territoriales involucradas en la aproximación al subsistema de agronegocios, y al circuito productivo sojero, componen el sustrato material de las relaciones de fuerzas sociales. Habiendo señalado previamente las tendencias a la concentración y también la heterogeneidad que compone la tipología de agentes, se hace necesario destacar la posición y función estratégica de dicho subsistema y circuito en su conjunto, terminando de configurar la relevancia de los procesos productivos.

Argentina se posiciona a nivel global como tercer productor de granos de soja y ocupa el primer lugar como exportador mundial de aceite y harina de soja. Asimismo, el hecho de que esta producción esté orientada en un $95 \%$ al mercado externo, en un contexto de altos precios de los commodities, le otorga al circuito sojero una posición estratégica en materia de comercio exterior. De hecho, para el año 2007 el complejo sojero llegó a explicar el 24,3\% de las exportaciones totales, y sumándole las exportaciones del complejo maicero y triguero alcanza casi un tercio (32,7 \%) de las ventas externas nacionales (Varesi, 2013). Así, la posición y función ocupada por los agentes del agronegocio, en general, y del circuito sojero en particular, los dotaba de un poder estratégico ligado a la provisión de divisas.

Pero si bien no es posible comprender las dinámicas del conflicto agrario de 2008 sin dar cuenta de su base estructural, tampoco puede ser reducido a esta, por lo que es necesario realizar un análisis de las relaciones de fuerzas políticas. Un factor que constituyó al conflicto agrario en hito histórico fue que este trascendió rápidamente el grado económico-corporativo de las relaciones de fuerzas políticas e ingresó en la fase superior de las mismas, convirtiéndose en un genuino antagonismo disputando la hegemonía y poniendo en debate aspectos nodales del proyecto de sociedad: el rol de Estado y el mercado, la estructura impositiva, la estrategia de desarrollo nacional y los grupos sociales indicados para conducirla, entre otros. Como todo antagonismo, la dinámica del conflicto estuvo atravesada por un proceso de polarización que abarcó toda la escena, con un polo agrario, conducido por las patronales del sector, y un polo oficialista, ligado al gobierno nacional.

El polo agrario adquirió la fortaleza de una conducción unificada en torno a la denominada Mesa de Enlace, que unía a las principales patronales del sector, incluso a dos que habían presentado serios enfrentamientos en el pasado, como la Sociedad Rural (SRA) y la Federación Agraria (FAA). Sin dudas, en esto incidió la transformación de la estructura social agraria, con la tendencia a la desaparición del pequeño arrendatario, otrora sujeto de la FAA, junto con la conversión a rentista de muchos pequeños productores. Aunque también, como señala Gras (2012), el empresariado rural se ha ido transformando en diversos aspectos, con el uso de biotecnología y el desarrollo de un tipo particular de gestión y organización, en un proceso hegemonizado por las franjas altas de dicha clase y que fue eficaz en incorporar a franjas intermedias, generando un proceso de reconstitución de fronteras sociales entre las distintas capas del empresariado, lo que permitió a su vez redefinir el escenario político gremial y las alianzas entre actores. En este trayecto, entidades como AAPRESID y AACREA desempeñaron un rol clave en materia de asesoramiento tecnológico y gestión empresarial, incluyendo el diseño de propuestas de políticas para el sector por parte de esta última y aportando a la homogeneización ideológica de los actores del subsistema de agronegocios. Esto influyó en el activo rol de los "auto-convocados", agentes de distinto tamaño y afiliación gremial que fueron dinámicos en organizar las acciones de protesta.

Para comprender la variación en las relaciones de fuerzas politicas debemos atender a cuatro ejes centrales. 1 En primer lugar, encontramos la construcción de un discurso tendiente a la homogeneización y a la polarización. Aquí, la significación y unidad en torno a la demanda central organizada en contra de las retenciones se convirtió en un elemento clave para habilitar la legitimidad del conflicto en ciernes y unir a los actores heterogéneos en un solo polo. Esto se debe a que, en términos globales, estamos frente a una demanda de una fracción que era beneficiaria del modelo de acumulación vigente y del contexto internacional, a tal 
punto que lo que estaba en juego, según datos de Arceo y Rodríguez (2008), era si el margen bruto por hectárea se incrementaba cerca del $45 \%$ con las retenciones móviles o más del $94 \%$ sin su aprobación, en relación a lo proyectado en el momento de siembra. En este sentido, la necesidad de presentar a los agentes del agronegocio como "perjudicados" implicaba dotar a las retenciones de un sentido "confiscatorio" de "neto corte fiscal" que expresaba un "ataque" desde el gobierno nacional al sector. Asimismo, según plantea Villulla:

En términos de consignas, los grandes terratenientes y burgueses agrarios trataron de reducir el programa del conflicto a su primer punto reivindicativo (el de la vuelta atrás con el nuevo esquema de retenciones), secundarizar la necesidad de segmentar las retenciones para los pequeños y medianos productores (...) y desde luego bloquear el paso a los sectores que ponían en discusión la perspectiva de una reforma agraria integral (2009, p. 23).

Además, la unidad en torno a la demanda contra las retenciones móviles se convirtió rápidamente en un cuestionamiento a las retenciones en su conjunto (algo incompatible con el propio funcionamiento del neodesarrollismo), lo que habilitó el paso de la disputa gremial a una batalla hegemónica de mayor alcance. Así, de forma creciente, la idea liberal de que la intervención del Estado introducía trabas distorsivas y de que eran los propios productores los mejores administrares de recursos, restablecía una perspectiva de libre mercado que había quedado desprestigiada durante la crisis de 2001 y que volvía a ganar terreno en la escena pública, cuestionando la forma adquirida por el Estado en la posconvertibilidad y su lógica de gestión del excedente, ligándose también con la perspectiva antiperonista.

En segundo lugar, encontramos la articulación de demandas más amplias que, si bien estaban subordinadas, permitían aportar homogeneización a un conjunto de actores estructuralmente heterogéneos: en este trayecto, el polo conducido por las patronales del agronegocio se convertía en "el campo". Aquí, el tándem homogeneización-universalización aportó otro factor clave a la estrategia hegemónica, ya que el campo aparecía ligado en el discurso a la idea de la Argentina como "granero (ahora oleaginoso) del mundo", recuperando un imaginario que ponía al agro como corazón de la nación habilitando la consigna "todos somos el campo". Asimismo, otra apelación a registros históricos del imaginario popular encontraba lugar en la asociación entre campo y federalismo, que delineaba al conflicto de 2008 como un nuevo capítulo del enfrentamiento entre el gobierno central y las provincias evocando la guerra civil entre unitarios y federales en el siglo XIX, ya que las patronales universalizadas como "campo" se arrogaban, en el discursos de sus dirigentes, la representación de "los pueblos del interior". De este modo, encontramos potencia y efectividad ideológica en una serie de asociaciones discursivas con gran capacidad de interpelación porque permitían vincular los fenómenos del presente en un registro histórico, al tiempo que cumplían con factores decisivos de las relaciones de fuerzas políticas: homogeneización en la conformación de conciencia política colectiva, en un trayecto de universalización que traspasaba los límites corporativos para proponerse como desarrollo de todas las energías nacionales.

Pero la potencia en el plano de las ideas no se realiza en un conflicto de tal magnitud sino es en la acción. Y es aquí donde se visualiza el tercer factor clave que permitió construir la victoria del polo agrario: la apelación a un vasto repertorio de acciones colectivas. Hallamos en 2008, sumado al lock-out patronal, una reapropiación de las más vastas acciones que las clases subalternas habían ido desarrollando en las luchas contra el neoliberalismo y que concluyeron en la rebelión popular de 2001. Sin dudas, la más relevante fue el "piquete": el corte de ruta desplegado por el movimiento de desocupados aparecía reapropiado por el polo agrario, mientras lo dotaba de un alcance único vinculado a las propias dinámicas territoriales del circuito sojero y habilitaba la diseminación de numerosos cortes en múltiples provincias. Así, la ampliación de la región del circuito vinculada a sus transformaciones productivas -en particular al paquete tecnológicoredundó en una ampliación del alcance de la acción colectiva, habilitando su nacionalización. Asimismo, las vinculaciones en términos del subsistema, como por ejemplo la derivación de excedentes del agronegocio al desarrollo inmobiliario en las principales ciudades o la propia localización de terratenientes, productores y financistas en dichas urbes, modificó la histórica relación campo-ciudad y permitió a su vez contar con apoyos en las urbes, incluso cuando los cortes de rutas comenzaban a generar desabastecimiento. Estos apoyos se 
transformaron en "cacerolazos" de estratos medios y altos urbanos, ya no contra los bancos como en 2001, sino en línea con el polo agrario. También proliferaron numerosas asambleas, como en aquellos años, pero ahora para organizar las medidas delineadas por la Mesa de Enlace y proponer acciones. Por último, una acción como el "escrache", antes utilizado por los organismos de DDHH para denunciar a los genocidas de la última dictadura que habían sido liberados en los años 90, en el 2008 se utilizó como método de presión contra los legisladores para condicionar su voto en el marco de la derivación de "la 125" al Congreso para su tratamiento como ley.

El cuarto factor, de carácter decisivo, fue el rol de los medios masivos de comunicación. Presenciamos un cambio que tendría consecuencias duraderas para la Argentina: varios de los principales grupos económicos de la comunicación, particularmente el Grupo Clarín, pasaron a alinearse explícitamente con las fuerzas opositoras emergentes. En aquella coyuntura, esto permitió dotar al polo agrario de una potencia hegemónica inédita, al cumplir estos medios el rol de intelectuales orgánicos al dar cohesión, promover sus intereses, plantear fines y alentar su organización. Debe notarse también "la confluencia de intereses económicos directos e indirectos entre empresas periodísticas y sectores de la producción agropecuaria” (Becerra y López, 2009, p. 11) que intensificaba dicha articulación. Así, el papel cumplido en la batalla ideológica puede verse en el tratamiento de las retenciones, el cual es subsumido a una confrontación entre propiedad privada e intereses del Estado (a través de argumentos como "es como si el Estado se quedara con el $40 \%$ de su sueldo"), promoviendo la analogía falaz entre la rentabilidad del agroexportador, en relación al ingreso salarial de cualquier trabajador; remarca la legitimidad de la demanda de este particular "campo" (Ibáñez y Cabral, 2008). Esto también se notó en la promoción de los dirigentes agrarios, su articulación con referentes de la oposición, la contraposición entre el tratamiento positivo dado a los mismos y las críticas implacables dirigidas contra CFK y los referentes del polo oficialista, como así también en la transmisión televisiva de los discursos de CFK en pantalla dividida, mostrando el malestar de los ruralistas en simultáneo (entre otros). Todo esto se dio, según Becerra y López (2009), en un escenario de escasez de fuentes, falta de espacio asignado a otras voces y construcción de un panorama de antagonistas sin matices. Los grandes medios reforzaron la polarización, pero jugaron deliberadamente para uno de los polos inclinando la balanza de relaciones de fuerzas políticas a su favor.

Frente a la sólida estrategia del polo agrario, el polo oficialista encontró un terreno difícil sobre el cual avanzar. Esto se debió a distintos factores.

En primer lugar, el pobre diseño original de la 125, que planteaba un esquema sin diferenciaciones, ayudó a homogeneizar lo que era heterogéneo y favoreció la conformación del adversario en un único polo. Además, se percibe lo que sería un elemento reincidente dentro del kirchnerismo hasta su derrota electoral en 2015: cierta subestimación del adversario. Parecía darse por descontado que las patronales agrarias no podían prevalecer. De hecho, CFK tardó casi dos semanas en hacer su primera referencia directa, cuando el 25 de marzo realizó el discurso donde contrapuso los "piquetes de la miseria", para referirse a 2001, y los "piquetes de la abundancia”, para caracterizar las medidas de fuerza del polo agrario, en lo que definió como un pasaje "de aquella tragedia a esto que parece casi un paso de comedia", quitando asílegitimidad al reclamo y reforzando la polarización y la confrontación en curso. Asimismo, en aquel discurso apareció la significación oficialista de la política de retenciones poniendo acento en su carácter distributivo, para lo cual se requiere captar recursos de sectores con renta extraordinaria y tocar intereses poderosos. Este también sería un factor característico del kirchnerismo sintetizado en sus líderes: el carácter popular que asumía el gobierno buscaba basamento en la defensa de los intereses de las mayorías.

Aquí se manifiesta el corazón de la estrategia hegemónica del kirchnerismo, la cual sintetizamos a partir de la doble lógica del populismo: a) como razón populista que busca articular demandas en una cadena equivalencial, definiendo la propia identidad a partir de la construcción de una frontera en la cual se delimita al adversario en el marco de la confrontación (recuperando críticamente los aportes de Laclau -2005- a la teoría de la hegemonía), y b) como pacto populista, ${ }^{2}$ que implica fortalecer el Estado para articular intereses 
entre fracciones de las clases dominantes (particularmente el capital productivo) y de las clases subalternas, desplegado entonces en el marco del proyecto de "crecimiento con inclusión social".

En este contexto, las retenciones eran identificadas como una pieza importante para redistribuir los excedentes, ligado al funcionamiento del régimen neodesarrollista, captar renta agraria para impulsar el proceso de reindustrialización, aumentar la inversión pública, desendeudar al país e implementar políticas sociales. Además, se reforzaría el argumento del rol de las retenciones para desacoplar precios internos y externos, limitando el impacto inflacionario local del aumento de precios internacionales, con su particular efecto sobre los alimentos, protegiendo la capacidad adquisitiva del salario. Otro elemento añadido sería un cuestionamiento a la creciente sojización, si bien debe notarse que no se explicitaba una crítica integral a las lógicas constitutivas del agronegocio.

En ese contexto, el gobierno iría sumando distintas adhesiones, desde corrientes ambientalistas, las dos centrales de trabajadores CGT y CTA, movimientos de desocupados, intelectuales de izquierda y progresistas y organismos de DDHH, entre otros (Villulla, 2009). Asimismo, se agregaron sectores campesinos excluidos por el agronegocio, y se conformó el espacio de intelectuales Carta Abierta, que caracterizaba la coyuntura como "una dura confrontación entre sectores económicos, políticos e ideológicos históricamente dominantes y un gobierno democrático que intenta determinadas reformas en la distribución de la renta y estrategias de intervención en la economía" (AAVV, 2008, p.1).

La construcción del adversario, que desde el gobierno de Néstor Kirchner aparecía conformado en las diversas figuras del régimen neoliberal, en el marco del conflicto agrario de 2008 aparecía redefinido en el discurso de CFK con las siguientes equivalencias enfrentadas: gobierno nacional = pueblo $=$ democracia versus oligarquía $=$ dictadura $=$ neoliberalismo. La ofensiva masiva de las patronales agrarias, articulada con los grandes medios de comunicación y los partidos opositores, llevó al oficialismo a caracterizar el conflicto como un intento de desestabilización que ponía en riesgo el orden democrático. En este sentido, CFK identificó la protesta agraria de 2008 con la de febrero de 1976, que constituyó un preludio del golpe de Estado, origen de la última dictadura que gestó las primeras reformas neoliberales. Con ello se completaba el tándem equivalencial en una interpelación al registro histórico: el enfrentamiento pueblo vs. oligarquía del peronismo clásico recreado en 2008 por el carácter sectorial, minoritario y poderoso de la cúpula agraria, se entrelazaba con la disyuntiva entre democracia (encarnada por el gobierno surgido en elecciones libres) y dictadura (por el potencial "golpista" que poseía la ofensiva desestabilizadora del polo agrario), lo cual se completaba con la disputa de proyectos societarios disímiles: el neodesarrollismo de corte nacional-popular vs. el retorno del neoliberalismo.

Pero si, por un lado, la polarización y confrontación permitió al kirchnerismo moldear su propia fisonomía política, la diferenciación tardía y poco efectiva que realizó en relación a los grupos agrarios limitó coyunturalmente su potencia hegemónica. Si bien ya en su segundo discurso CFK buscó distinguir entre los pequeños y medianos productores y los grandes terratenientes y pools de siembra, la polarización ya manifestada, sumada a la potente estrategia del adversario y el rol de los medios de comunicación, complicaron el objetivo de lograr intervenir sobre la heterogeneidad estructural y convertirla en heterogeneidad política.

En relación a las acciones desplegadas, según consigna Sanz Cervino (2012), en los primeros días del conflicto el gobierno privilegió los pronunciamientos públicos y recién 21 días después comenzó a apostar por la movilización en las calles, convocando a Plaza de Mayo el 1 de abril y en adelante en distintos momentos. Sin embargo, no lograba equiparar la capacidad de convocatoria del polo agrario.

La inclusión de reformas compensatorias para pequeños productores de la Resolución 284, y para provincias extra-pampeanas por lejanía a puertos de la Resolución 285 del Ministerio de Economía (del 18 de abril), parecían no ser suficientes para torcer el rumbo del conflicto. Así, otro momento clave fue la renuncia el 24 de abril del ministro Lousteau, elaborador de la 125, como intento de descomprimir el enfrentamiento que ya se acercaba al mes y medio de duración. Sin embargo, más allá de treguas coyunturales, la negativa 
a eliminar el nuevo esquema de retenciones, que constituía la demanda central del polo agrario, sostenía el reclamo en su multiplicidad de acciones colectivas. Aún cuando la propuesta de destinar parte de lo recaudado por retenciones a planes de vivienda, salud e infraestructura permitía reforzar el significado popular de la medida fortaleciendo la adhesión de los grupos que ya formaban parte de la coalición oficial, por otro, los reintegros a pequeños productores o la eliminación de la cláusula "tope" de 600 dólares, no lograban hacer mella en el polo agrario.

En ese contexto, el gobierno realizó su apuesta final: el 17 de junio envió la 125 al Congreso para que fuese tratada como proyecto de ley. De ese modo remarcaba el carácter democrático del polo oficialista en un escenario que permitiría legitimar la medida y que a priori no debía presentar mayores complicaciones ya que el kirchnerismo contaba con mayoría en las dos cámaras. Pero el polo agrario seguiría incluso en ese contexto volcando las relaciones de fuerzas políticas a su favor. En un primer momento, el tratamiento (y aprobación) en la Cámara de Diputados se efectuó ampliando las compensaciones, las cuales incluían una mejor segmentación de retenciones por tamaño y aquellas por distancia a puerto, así como un Fondo de Redistribución social para salud, vivienda y caminos rurales, entre otras. En su segundo y final momento, la pérdida de adhesiones del polo oficialista en el marco de la creciente ofensiva agraria implicó no sólo la pérdida de votos de senadores previamente oficialistas, sino del propio vicepresidente Cobos quien desempataría en contra del gobierno del cual formaba parte con su célebre "voto no positivo", dando por tierra con el proyecto y sentenciando la derrota el 18 de julio de 2008, tras 129 días de conflicto.

\section{Consideraciones finales}

El conflicto de 2008 marca la particularidad de que los agentes económicos y las representaciones corporativas vinculados al circuito productivo sojero que salieron a enfrentar al gobierno constituían una de las fracciones de clase ascendentes que, más allá de las retenciones, eran beneficiarios del régimen neodesarrollista. Aquí debemos notar que, a raíz de largos procesos de concentración y de transformación productiva ligados al agronegocio que actuó como factor de unificación, estos grupos acumularon suficiente poder estructural, volcando a su favor las relaciones de fuerzas sociales, como para salir a la confrontación abierta para defender sus intereses sectoriales y buscar su "universalización" en la arena política.

Así, el proceso de lucha dio origen a la conformación de un alineamiento opositor que comenzaba a plasmar una rearticulación dentro del bloque de poder, donde los agentes del agronegocio, sus corporaciones, junto a los partidos opositores, tuvieron a los grandes grupos económicos de la comunicación, particularmente al Grupo Clarín, como intelectuales orgánicos destacados.

El triunfo agrario tuvo lugar primero tanto en el plano ideológico como en las calles, a través de una amplia gama de acciones colectivas que gestaron una prolífica activación de diversos sectores de la sociedad civil que desplegaron corte de rutas, asambleas, movilizaciones, escraches a legisladores, entre otras acciones. Se produjeron, así, avances en las más variadas trincheras de la batalla hegemónica hasta llegar al propio Congreso, donde finalmente se liquidó la estrategia oficial de generar una mayor captación de renta agraria para transferir y aceitar otros engranajes del modelo de acumulación que se percibían claves para el desarrollo, como la industria.

Según Barri y Wahren (2010), se presentó la paradoja de que con la caída del proyecto de ley de retenciones móviles diferenciadas, la franja de 45.000 productores medianos y chicos, concentrados principalmente en la "zona sojera" del país, y que conformaron el sector más importante de los cortes de ruta, se vieron perjudicados por la pérdida de los beneficios impositivos que estaban incluidos en el proyecto, por lo cual terminaron perdiendo para fines de 2008 un $10 \%$ más que lo previsto en dicho proyecto. Se hace manifiesto entonces la necesidad de problematizar el efecto de la homogeneización hegemónica de aquello que estructuralmente es heterogéneo y asimétrico. Según planteaba Gramsci, la homogeneidad, la organización y la conciencia colectiva son tres claves para analizar la variación en las relaciones de fuerzas políticas. La mera nominación 
del diverso mundo agrario como "el campo", y su identificación con las patronales del agronegocio, marcaron un primer éxito hegemónico que les permitió conformar un polo unificado. Unidad que además se abigarró en torno a la demanda central contra las retenciones y subordinó otros reclamos, aun cuando su articulación permitía esa universalización de intereses potenciada por una efectiva (y también afectiva) apelación a registros históricos como el federalismo y la Argentina como "granero del mundo". Aunque, sin dudas, el factor decisivo fue la acción colectiva amplia, contundente y sostenida que llevó al polo agrario a la victoria, sumada al efecto de legitimación y conducción ideológica de los grandes medios de comunicación.

Para el oficialismo, signado por la doble lógica del populismo, este antagonismo tenía impactos tanto en la propia conformación identitaria como en los rasgos que podía adquirir, con el cambio de coyuntura, la estrategia de pacto social. La derrota de 2008 conllevó no sólo un desgrane de la fuerza oficialista, al perder el apoyo de legisladores, sepultar al Ministro de Economía y desgastar al Jefe de Gabinete, Alberto Fernández, quien dejaría su lugar al finalizar el conflicto, sino que incluso terminó con el pasaje del vicepresidente a la oposición. La crisis política se agravaría luego con la derrota del kirchnerismo en las legislativas de 2009. Allí, según Gras (2012), la estrategia del polo agrario fue participar electoralmente incorporándose a distintos partidos de la oposición, llegando a nivel nacional a obtener 18 legisladores (vinculados a CRA, SRA y FAA) en representación de 11 provincias.

También debe recordarse que desde lo más profundo de aquella derrota política, complejizada además en lo económico por el impacto de la crisis mundial, el kirchnerismo daría lugar a un audaz proceso de recomposición hegemónica, lanzando un vasto plan anticrisis y radicalizando las políticas de ampliación de derechos, distribución del ingreso e inclusión social, que permitieron a CFK lograr el 54 \% de los votos en 2011. Sin embargo, el carácter de hito establecido por el conflicto de 2008 fue tal que en 2015 el kirchnerismo sería derrotado por una fuerza emergente de aquel conflicto que dividió al país. Así, el gobierno de Cambiemos aplicó políticas deliberadamente favorables al agronegocio, combinando megadevaluaciones con reducción de retenciones a soja y eliminación masiva de las restantes, reorganizando el bloque de poder de modo favorable también a los agentes del capital financiero y las empresas de servicios privatizadas, y actuando en desmedro de la coalición policlasista que representaba el kirchnerismo, con un fuerte embate contra la industria, las PyMEs y principalmente contra la masa de las clases subalternas en un deterioro de ingresos y derechos acelerado, en lo que podemos caracterizar como un proceso de restauración neoliberal.

Para finalizar podemos trazar algunas preguntas para interpelar la coyuntura actual. ¿Qué escenario podrá trazarse con el gobierno del Frente de Todos? ¿Será capaz de forjar una construcción hegemónica que convoque a los pequeños y medianos productores agrarios así como a los trabajadores rurales? ¿Se abrirán debates sobre las lógicas productivas que rigen el agronegocio en Argentina y/o sobre la desigualdad estructural que lo atraviesa? ¿Qué rol jugarán las retenciones? ¿Cómo responderán las patronales agrarias frente a las políticas relativas al sector?

Sin dudas algunas de las tensiones que afectarán este escenario se darán entre la búsqueda de soberanía nacional y la dependencia tecnológica, entre la estructura exportadora agroalimentaria y el precio interno de los alimentos; entre la necesidad de divisas para superar la restricción externa y el debate en torno a las aristas más perniciosas del agronegocio, como su concentración, el efecto sobre el medio ambiente y la salud, etc., y la propuesta de alternativas que sean no sólo ecológicas sino también económicamente sustentables.

\section{FUENTES UTILIZADAS}

AAVV (15 de mayo de 2008). Carta Abierta / 1. Página 12. Recuperado de https://www.pagina12.com.ar/diario/e lpais/1-104188-2008-05-15.html

Argentina. Ministerio de Agricultura, Ganadería y Pesca. Estimaciones agrícolas. Recuperado de https://www.magy p.gob.ar/sitio/areas/estimaciones/ 
Argentina. Ministerio de Economía y Finanzas Públicas. (2011). Complejo Oleaginoso. Recuperado de http://www. mecon.gov.ar/peconomica/docs/Complejo_Oleaginoso.pdf

Defensoría del Pueblo PBA y Universidad Nacional de la Plata. (2015). Relevamiento de la utilización de agroquímicos en la Provincia de Buenos Aires. Recuperado de https://www.agro.unlp.edu.ar/sites/default/files/paginas/info rme_agroquimicos_comprimido.pdf

Instituto Nacional de Tecnología Agropecuaria. (2011). Siembra Directa. Recuperado de https://inta.gob.ar/sites/d efault/files/script-tmp-siembra_directa_2011.pdf

PwC Argentina Research \& Knowledge Center (2013). Análisis Sectorial n. ${ }^{\circ} 1$ Maquinaria Agrícola. Argentina.

\section{ReFERENCIAS}

Albiol, C. (2013). Impactos geográficos de la sojización en Argentina. Mendoza: Biblioteca Digital UNCuyo. Recuperado de http://bdigital.uncu.edu.ar/6346.

Amaya Guerrero, R. (2014). Concentración exportadora en el complejo sojero argentino (1996-2010). Revista de Economia y Comercio Internacional, 4, 25-44.

Arceo, N. y Rodríguez, J. (16 de marzo de 2008). Inflación, retenciones y rentabilidad agrícola. Ganan como nunca. Página 12.

Arrillaga, H. y Delfino, A. (2009). Agriculturización, inequidad distributiva y fractura del tejido social. Revista de estudios regionales y mercado de trabajo, 5, 225-250.

Balsa, J. (2008). Transformaciones en la agricultura pampeana en las últimas décadas y su relación con el conflicto agrario. Trabajo presentado en X Jornadas de Investigación del Centro de Investigaciones Geográficas, La Plata.

Bandieri, S. (2005). La posibilidad operativa de la construcción histórica regional o cómo contribuir a una historia nacional más complejizada. En S. Fernández y G. Dalla Corte (Comps.), Lugares para la historia. Espacio, historia regional e historia local en los estudios contemporáneos. Rosario: UNR Editora.

Barri, F. y Wahren, J. (2010). El modelo sojero de desarrollo en Argentina: tensiones y conflictos en la era del neocolonialismo de los agro-negocios y el cientificismo-tecnológico. Realidad Económica, 255.

Barsky, O. y Dávila, M. (2008). La rebelión del campo. Historia del conflicto agrario argentino. Buenos Aires: Sudamericana.

Basualdo, E. (2008). El agro pampeano: sustento económico y social del actual conflicto en la Argentina. Cuadernos del CENDES, 68, 29-54.

Becerra, M. y López, S. (2009). La contienda mediática: Temas, fuentes y actores en la prensa por el conflicto entre el gobierno y las entidades del campo argentino en 2008. Revista de Ciencias Sociales, 1(16), 9-30.

Bil, D. (2017). Análisis de la producción y del comercio de maquinaria agrícola argentina en la competencia regional (2002-2014). tiempoßeconomía, 4 (1), 101-124.

Bisang, R. (2008). La agricultura argentina: cambios recientes, desafíos futuros y conflictos latentes. ARI Real Instituto Elcano, 111, 1-7.

Blanco, J. (2007). Espacio y territorio: elementos teórico-conceptuales implicados en el análisis geográfico. En V. Fernández Caso y R. Gurevich (coord.), Geografia. Nuevos temas, nuevas preguntas. Buenos Aires: Ed. Biblos.

Bugallo, L. (2012). El Sector Agroindustrial en Argentina: del PBI a la Balanza Comercial. Recuperado de https://es.s cribd.com/doc/92616832/El-Sector-Agroindustrial-Argentino-del-PBI-a-la-Balanza-Comercial

Burgos, M., Mattos E. y Medina A. (2014). La soja en Argentina (1990-2013): cambios en la cadena de valor y nueva articulación de los actores sociales. Documentos de Trabajo CEFIDAR, 63.

Bustamante, M. y Maldonado, G. (2009). Actores sociales en el agro pampeano argentino hoy. Algunos aportes para su tipificación. Cuadernos Geográficos, 44(1), 171-191.

Crespo, E. (1998). El capital tecnológico de P. Levín. Realidad Económica, 156.

De Jong, G. (1981). El análisis regional: consideraciones metodológicas. Boletín Geográfico, 8. 
De Jong, G. (2001). Introducción al método regional. Neuquén: LIPAT, UNCo.

De Jong, G. (2009). Apuntes de Cátedra: Las relaciones sociales directas de acumulación desigual de excedentes y los mecanismos de la reproducción ampliada del capital. Mimeo. FaHCE-UNLP.

Domínguez, N. y Orsini, G. (2009). El conflicto rural, su relación con el modelo hegemónico sojero y la estructura agraria vigente. Pampa, 5, 219-237.

Fair Rzezak, H. (2008). El conflicto entre el gobierno y el campo en argentina. Lineamientos políticos, estrategias discursivas y discusiones teóricas a partir de un abordaje multidisciplinar. Iberoforum, 6, 82-106.

García A. y Rofman A. (2008). Agribusiness y fragmentación en el agro argentino: desde la marginación hacia una propuesta alternativa. Mundo Agrario, 10(19).

Giarracca, N., Teubal, M. y Palmisano, T. (2008). Paro agrario: crónica de un conflicto alargado. Realidad Económica, 237, 33-54.

Godio, J. y Robles, A. (2008). El tiempo de CFK. Entre la movilización y la institucionalidad. El desafío de organizar los mercados. Buenos Aires: Corregidor.

Gramsci, A. (2017). Notas sobre Maquiavelo, sobre la politica y sobre el Estado moderno. Buenos Aires: EDICOL y Libros de la Araucaria.

Gras, C. (2012). Empresarios rurales y acción política en Argentina. Estudios Sociológicos, 30(89), 459-487.

Gras, C. y Hernández, V. (2009). "Son lospiquetes de la abundancia" Actores y Estado en el conflicto agrario en Argentina. Trabajo presentado en Congreso de la Asociación de Estudios Latinoamericanos, Rio de Janeiro, Brasil.

Ibáñez, I. y Cabral, X. (2008). Entre apuntadores y guionistas: el papel de los medios en el conflicto campo/gobierno. Boletin Onteaiken, 5, 5-10.

Laclau, E. (2005). La razón populista. Buenos Aires: FCE.

Langard, F. (2016). Producción de maquinaria agrícola en Argentina: análisis comparado de las dinámicas de los conglomerados nacionales y de las cadenas globales de valor. Trabajo y Sociedad, 27, 405-424.

Levín, P. (1981). Diseño de subsistemas. Boletín geográfico, 8.

Llovera, G. (2006). Competitividad del acopio. Trabajo presentado en el III Congreso de Soja del Mercosur, Rosario, Argentina.

Manzanal, M. y Arzeno M. (2010). Conflictos territoriales en ámbitos rurales en la Argentina actual. Espaço e Tempo, $28,197-218$.

Marx, K. y Engels, F. (1985) [1846]. La Ideología Alemana. Buenos Aires: Cartago

Marx, K. y Engels, F. 1960 [1948]. El Manifiesto Comunista. La Habana: Ed. Sociales.

Mengo, R. y Pizarro, H. (2010). El discurso oficial en el conflicto entre el gobierno y el campo argentino. Educación y Humanidades, 1, 88-120.

Palma, A. (2011). Las oposiciones léxicas en el discurso de Alfredo De Angeli: análisis de las funciones estratégicas y la construcción de destinatarios durante el conflicto agrario argentino del año 2008. Trabajo presentado al V Coloquio de Investigadores en Estudios del Discurso, Universidad Nacional de Villa María.

Perelmuter, T. (2018). Propiedad intelectual en semillas: los dispositivos del cercamiento jurídico en Argentina. Mundo Agrario, 19(42).

Pérez Trento, N. (2019). Dos décadas de conflicto en torno al uso propio de semillas de soja genéticamente modificada en Argentina: fases del enfrentamiento, acumulación de capital y actores sociales (1996-2018). Mundo Agrario, 20(43).

Piergentilli, N. y Dossi M. (2014). Complejo agroindustrial de la soja en Argentina. Antecedentes y evolución en el período 2002-2010. Apuntes Agroeconómicos, 8(10).

Pierri, J. y Abramovsky M. (2011). El complejo sojero ¿̨una economía de enclave sui generis del siglo XXI? Realidad Económica, 259.

Rajland, B. (2008). El pacto populista en la Argentina (1945-1955). Proyección teórico-politica hacia la actualidad. Buenos Aires: Ediciones del CCC. 
Rebagliati, R. (2017). Genética, semillas y regalías. Nuevos Papeles. Recuperado de https://www.nuevospapeles.com/ nota/6844-genetica-semillas-y-regalias

Reboratti, C. (2003). Desarrollo regional y territorios privatizados. En C. Acuña y A. Riella, Territorio, sociedad y región. Montevideo: Rosgal.

Reboratti, C. (2010). Un mar de soja: la nueva agricultura en Argentina y sus consecuencias. Revista de Geografía Norte Grande, 45, 63-76.

Rofman, A. (1984). Subsistemas espaciales y circuitos de acumulación regional. Revista interamericana de planificación, 18(70), 42-61.

Rofman, A. (1999). Las economías regionales a fines del siglo XX. Los circuitos de petróleo, el carbón y el azúcar. Buenos Aires: Ariel.

Romero, F. (2014). Los agroquímicos: concentración y dependencia en la Argentina (1976-2014). Revista Interdisciplinaria de Estudios Agrarios, 41, 59-101.

Sánchez, J. (1991). Espacio, economia y sociedad. Madrid: Siglo XXI.

Sanz Cervino, G. (2012). Burguesía agraria, conflictividad política y quiebres institucionales. Argentina, 1975-2008. Polis Revista Latinoamericana, 31.

Schvarzer, J. y Tavosnanska A. (2007). El complejo sojero argentino. Evolución y perspectivas. Documento de Trabajo CESP, 10.

Teubal M. y Palmisano, T. (2010). El conflicto agrario en la Argentina (2008/2010): sojización vs. agricultura familiar de alimentos. Trabajo presentado en VIII Congreso Latinoamericano de Sociología Rural, Porto de Galinhas, Brasil.

Trucco, I. (2012). El enfoque de los subsistemas de acumulación y los estudios regionales contemporáneos. Reflexiones conceptuales y metodológicas. En II Jornadas Nacionales sobre Estudios Regionales y Mercados de Trabajo, Santa Fe.

Varesi, G. (2010). El circuito productivo sojero argentino en el modelo post-convertibilidad. Una aproximación desde el enfoque de análisis regional. Cuadernos del CENDES, 74, 107-137.

Varesi, G. (2013). Modelo de acumulación y hegemonía en la Argentina post-convertibilidad, 2002-2008 (Tesis de Doctorado). FAHCE-UNLP. Recuperado de http://sedici.unlp.edu.ar/handle/10915/26869

Varesi, G. (2014). El “conflicto del campo" de 2008 en Argentina: hegemonía, acumulación y territorio. Geograficando, $10(2)$.

Villulla, J. (2009). Apuntes críticos para el debate sobre el conflicto agrario de 2008. Trabajo presentado en VI Jornadas Interdisciplinarias de Estudios Agrarios y Agroindustriales FCE-UBA. Buenos Aires.

Zunino, E. y Aruguete N. (2012). La responsabilidad de los actores en la cobertura mediática del "conflicto del campo" de 2008: un estudio de caso a partir de la realidad argentina. Intersecciones en Comunicación, 6.

\section{Notas}

1 Sintetizamos aquí elementos de trabajos previos (Varesi, 2013 y 2014) en una combinación con nuevos avances.

2 Remitimos aquí al concepto desarrollado por Rajland (2008). 